\title{
Signs of Depression Following Laparoscopic Gastric Banding
}

\section{Journal of \\ Obesity and Bariatrics}

\author{
Adi Manor ${ }^{1}$, Boris Nemetz ${ }^{2}$, Zvi Perry ${ }^{1}$ and Boris \\ Kirshtein ${ }^{1 *}$ \\ ${ }^{1}$ Department of Surgery A, Soroka University Medical Center, \\ Faculty of the Health Sciences, Ben-Gurion University of the Negev, \\ Beer-Sheva, Israel \\ ${ }^{2}$ Department of Psychiatry, Beer-Sheva Mental Health Center, \\ Faculty of the Health Sciences, Ben-Gurion University of the Negev, \\ Beer-Sheva, Israel
}

\begin{abstract}
Background: Long-tem outcomes of laparoscopic gastric banding ( $L G B$ ) related to depression and predictors of changes in depression are still unclear. Our goal was to investigate signs of depression a fter LGB.

Methods: Two hundred three patients who underwent LGB for treatment of morbid obesity in our department between January 1997 and December 2008 were investigated, using the Patient Health Questionnaire 9 (PHQ-9) to assess and measure the severity of depression following surgery. Additional data was collected from patients' charts and telephone questionnaire and included demographic data, psychiatric illness and treatment before surgery, BMI before LGB and at the time of interview, \% excess weight loss (\%EWL), and primary bariatric and additional surgery for repair, reposition, and exchange of the band.
\end{abstract}

Results: A significant correlation was found between PHQ-9 score and weight loss after surgery measured by \%EWL $(p<0.001)$ and selfesteem-after the surgery $(p<0.01)$. Self-esteem after the surgery was significantly correlated with \%EWL $(p=0.001)$. Men's self-esteem before surgery was significantly higher than women's $(p=0.037)$, while selfesteem after surgery was the same in both groups. PHQ-9 score was significantly higher in women than in men, 5.34 and 3.39 , respectively $(\mathrm{p}=0.01)$.

Conclusions: Among predictive variables checked for changes in symptoms of depression, weight loss had the greatest impact on symptoms of depression and quality of life. Success at weight loss correlated with lower risk for developing symptoms of depression, higher self-esteem after surgery, and greater satisfaction from the procedure. We recommend closed follow-up and psychologist involvement for women because they had a greater tendency for developing symptoms of depression.

\section{Introduction}

Overweight and obesity have become a serious worldwide problem in public health; over one billion adults around the world are overweight, and at least 300 million of them suffer from obesity. The prevalence of obesity is increasing to an extent that the World Health Organization has described it as an epidemic affecting most developed and developing countries [1]. As the prevalence of obesity increases, bariatric procedures have been shown to be more effective in the management of morbid obesity compared to medical treatments in terms of weight loss and its sustainability [2]. Laparoscopic gastric banding procedure (LGB) has gained popularity as the least invasive form of surgical treatment for morbid obesity.

Obesity has a major impact on the physical, mental, psychosocial, and economic health of the patients, but the nature of the relationship between obesity and depression, or between weight loss and depression remains unclear. Nineteen to $28 \%$ of patients who sought bariatric surgery had a lifetime history of major depressive disorder [3]. Results concerning improvement in depression and quality of life after significant weight loss following bariatric surgery are inconsistent and not all studies found an overall positive outcome in depression: some studies reported an improvement [4-7]; however,

\section{*Address for Correspondence}

Boris Kirshtein, Department of Surgery "A", Soroka University Medical Center, POB 151, Beer-Sheva, 84101 Israel, Tel: +972-8-640-0267; Fax: +972-8-640-3260; E-mail: borkirsh@bgu.ac.il

Copyright: (c) 2014 Manor A, et al. This is an open access article distributed under the Creative Commons Attribution License, which permits unrestricted use, distribution, and reproduction in any medium, provided the original work is properly cited.

Submission: 08 October 2014

Accepted: 20 October 2014

Published: 24 October 2014

Reviewed \& Approved by: Dr. Francesco Saverio Papadia, Department of Surgery, University of Genoa School of Medicine, Italy.

some reported a return to preoperative status [8] or even an increase of depression after gastroplasty [9]. Most studies included followup of 12 to 36 months $[3,8]$, which may be considered too short for obtaining definitive results. Nonetheless, long-term outcome studies with follow up of more than 5 years investigating changes in depression are rare [4].

The aims of our study were to assess and evaluate changes in symptoms of depression and self-acceptance 1-11 years after surgery; to determine predictive variables (e.g., preoperative weight and weight loss, \%EWL) for changes in symptoms of depression; and to compare gender influences on surgical success and symptoms of depression.

\section{Patients and Methods}

This research was approved by the Helsinki Committee of Soroka University Medical Center. In a cross-sectional study, the data of patients who underwent LGB at the Department of Surgery "A", Soroka University Medical Center, Beer-Sheva, Israel, between January 1997 and December 2008, was collected from the hospital computerized database. All patients were older than 18 years on the day of surgery and completed at least one-year follow up after the LGB.

We performed a telephone interview during which the following data was gathered: weight and body mass index (BMI) on the day of the interview, quality of life measures (surgery satisfaction, frequency of vomiting, self-acceptance before and after the surgery using a scale of 1to 10), frequency of port inflations, redo surgery, previous bariatric procedures, and Patient Health Questionnaire 9 (PHQ-9) score. Preoperative demographic data, BMI, and comorbidities were collected from the medical charts.

PHQ-9 score was used as a measure of the severity of depression. It is a 9-item self-reported questionnaire designed to evaluate the presence of depressive symptoms (during the previous 2 weeks), and was found to be reliable when administered by phone [10]. Each of the 9 items, asking about each of the Diagnostic and Statistical Manuals 
of Mental Disorders, Fourth Edition (DSM-IV) diagnostic criteria, can be scored from 0 (not at all) to 3 (nearly every day). As a severity measure, scores can range from 0 (absence of depressive symptoms) to 27 (severe depressive symptoms).

As a measure of weight loss we used percent excess weight loss $(\% \mathrm{EWL})$. The values of ideal body weight $(\mathrm{IBW}(\mathrm{kg})=50 \mathrm{~kg}$ for men and $45 \mathrm{~kg}$ for women $+2.3 \mathrm{~kg}$ per inch above 5 feet), and excess body weight $(\mathrm{EBW}(\mathrm{kg})=$ weight-IBW) were used to calculate $\% \mathrm{EWL}=$ (weight on the day of interview-IBW)/EBW $\times 100$ [3].

In order to study the influence of time since the operation on depression symptoms, we divided our patients into 4 groupsdepending time since the surgery: group A 1 to 3 years, group B 4 to 6 years, group $\mathrm{C} 7$ to 9 years, and group $\mathrm{D}$ at least 10 years. During the study period 3230 patients underwent LGB in our service: 147 from 1996 to 1998,726 from 1999 to 2001, 1026 from 2002 to 2004, and 1331 from 2005 to 2008. In order to evaluate the number of patients needed to be investigated we used a sample size computer program (WINPEPI) under the following assumptions: The ratio between the study groups was assumed to be $1: 1, \alpha=0.05, \beta=0.8$; the standard deviation in each group was believed to be 5 ; and the minimal difference to be detected was 3 . These assumptions were taken from a prior validation of the PHQ-9 [11]. Under these assumptions each group needed at least 45 patients in each group, or at least 180 patients in all groups.

\section{Statistical Analysis}

The case information was coded and stored in a Microsoft Office
Excel file and transferred to the SPSS 17.0 program. The data was first analyzed using descriptive statistics (using the appropriate central and distribution indices).

Comparison between groups was performed using the Pearson chi square test for nominal variables, and Fisher's exact test for dichotomous variables (when applicable).

Comparison of quantitative variables was done with the parametric t-test when appropriate; for a-parametric tests, we used the Mann-Whitney test. Correlations were measured with Pearson's correlation for parametric variables and Spearman's correlation for a-parametric variables. Statistical significance was considered when $\mathrm{p}$ value was $<0.05$.

\section{Results}

Between January 1997 and December 2008 approximately 3,000 LGB procedures were performed. At follow up, overall 203 patients (75 men and 128 women) responded to the phone interview and were included in our research. The patients' mean age at the time of surgery was $37.9 \pm 10.7$ years. Patient characteristics are shown in Table 1. One hundred four patients (51.2\%) had comorbidities with prevalence of hypertension (17.2\%), diabetes (13.8\%), hypercholesterolemia (10.8\%), and obstructive sleep apnea (7.4\%). Of these, 58(55.8\%) suffered from more than one additional disease. Only $0.5 \%$ of patients had a history of psychiatric disorders.

Sixty-one of 203 patients (30\%) required redo surgery, 15 (7.4\%) had a second operation, and $3(1.5 \%)$ a third. The most frequent

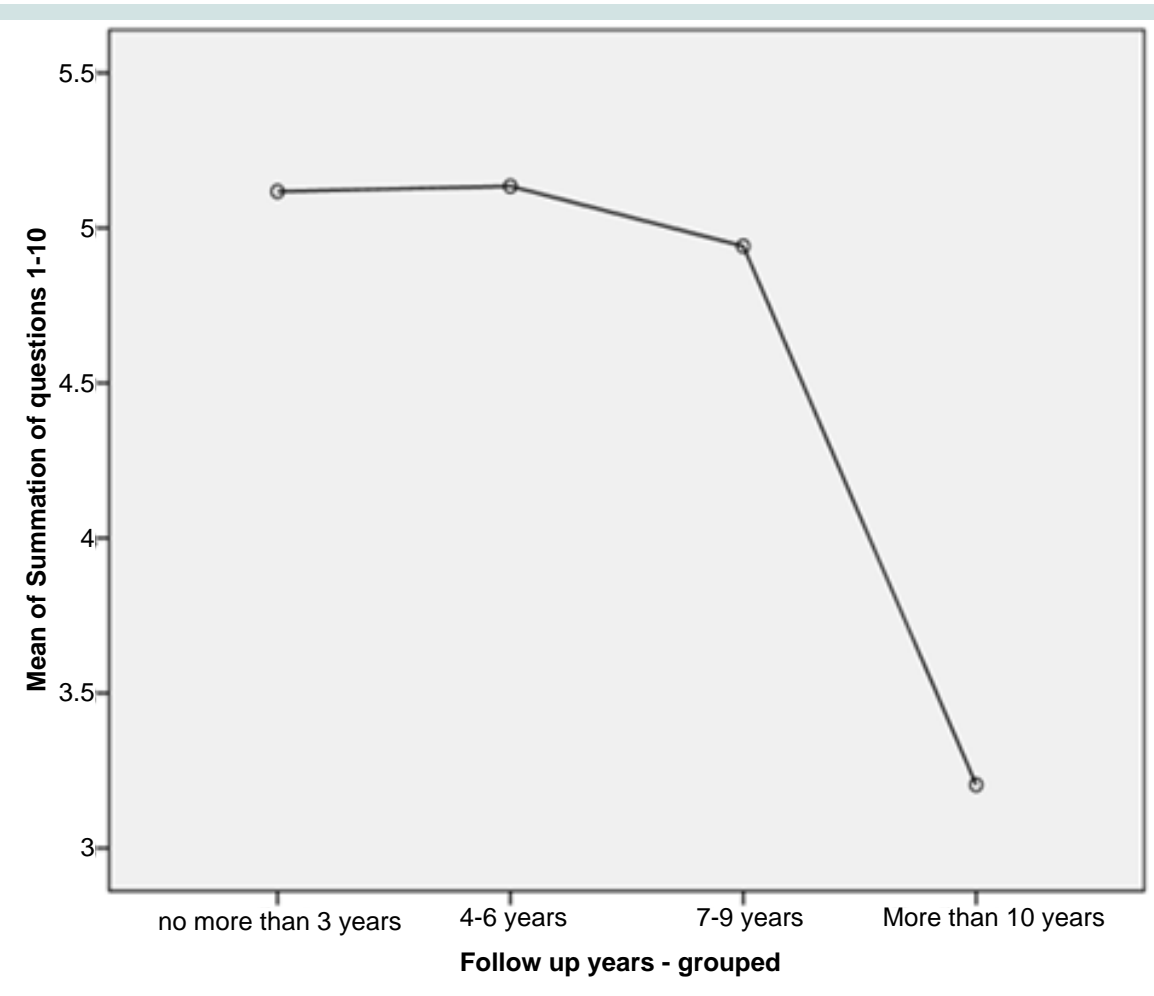

Figure 1: Mean PHQ-9 score according the 4 sub-groups. 
reason for the redo operation was band slippage (20.2\%). Other causes for repeated surgery included band replacement (4.9\%), reposition of port (2.5\%), and band erosion (1\%).

PHQ-9 scores and quality of life scores are presented in Table 2. Lower PHQ-9 score correlated well with higher self-esteem after surgery $(\mathrm{p}<0.01, \mathrm{r}=-0.374)$, and the average PHQ-9 score was significantly lower among patients who were satisfied with the procedure (4.1 vs. $8.1, \mathrm{p}=0.01)$.

\%EWL significantly correlated with both PHQ-9 score and patient's self-acceptance- higher \%EWL correlated with lower PHQ9 score $(\mathrm{p}=0.001, \mathrm{r}=-0.223)$, higher self-esteem after surgery $(\mathrm{p}=0.001$, $\mathrm{r}=0.244)$, and lower self-esteem before surgery $(\mathrm{p}=0.008, \mathrm{r}=-0.203)$. However, age, time since the operation, number of redo operations, frequency of vomiting, and number of port inflations did not predict significant changes in PHQ-9 score.

Clinical and demographic characteristics of men and women are shown in Table 3. The two groups were similar regarding preand post-operative BMI, \%EWL, number of redo surgeries, and comorbidities. Women had a significantly higher PHQ-9 score than men (5.3 vs. $3.4, p=0.01$ ), and had significantly lower self-esteem before surgery ( 4.4 vs. $5.4, \mathrm{p}=0.03$ ), although the average self-esteem after surgery was similar between the genders.

Comparing the four subgroups of patients according to time since the operation, we did not find a difference in terms of preoperative
BMI, gender, age, and comorbidities. The need for redo surgery and number of redo procedures, however, significantly increased throughout the years; most patients in group D underwent at least one reoperation $(79.6 \%)$, and only in this group $3(4.9 \%)$ patients required a third operation. \%EWL is also was significantly higher with years from primary LGB. There was no statistically significant difference between groups regarding PHQ-9 score; however, there was a tendency for a decrease in score through the years (Figure 1).

\section{Discussion}

Our study focused on investigating symptoms of depression in obese patients after LGB procedure, and on finding predictors to post-surgical depression during long-term follow-up.

We found that success in weight loss (\%EWL) had the greatest impact on both symptoms of depression and self-acceptance; success in weight loss correlated with lower risk for developing symptoms of depression, higher self-esteem after surgery, and greater satisfaction from the procedure. The relationship between weight loss and symptoms of depression is controversial in different studies. While Dixon et al. used the BDI (Beck Depression Inventory) questionnaire to evaluate pre- and post-surgical depression, and found that subjects losing more weight had greater falls in their BDI scores one year after surgery [5], Waters et al. used the HIS-GBW (Health Insurance Study- General Well-Being) battery to test mental health one-half, one, two, and three years following gastric bypass procedure and found significant improvement in mental health indices 6 and 12

Table 1: Patient characteristics.

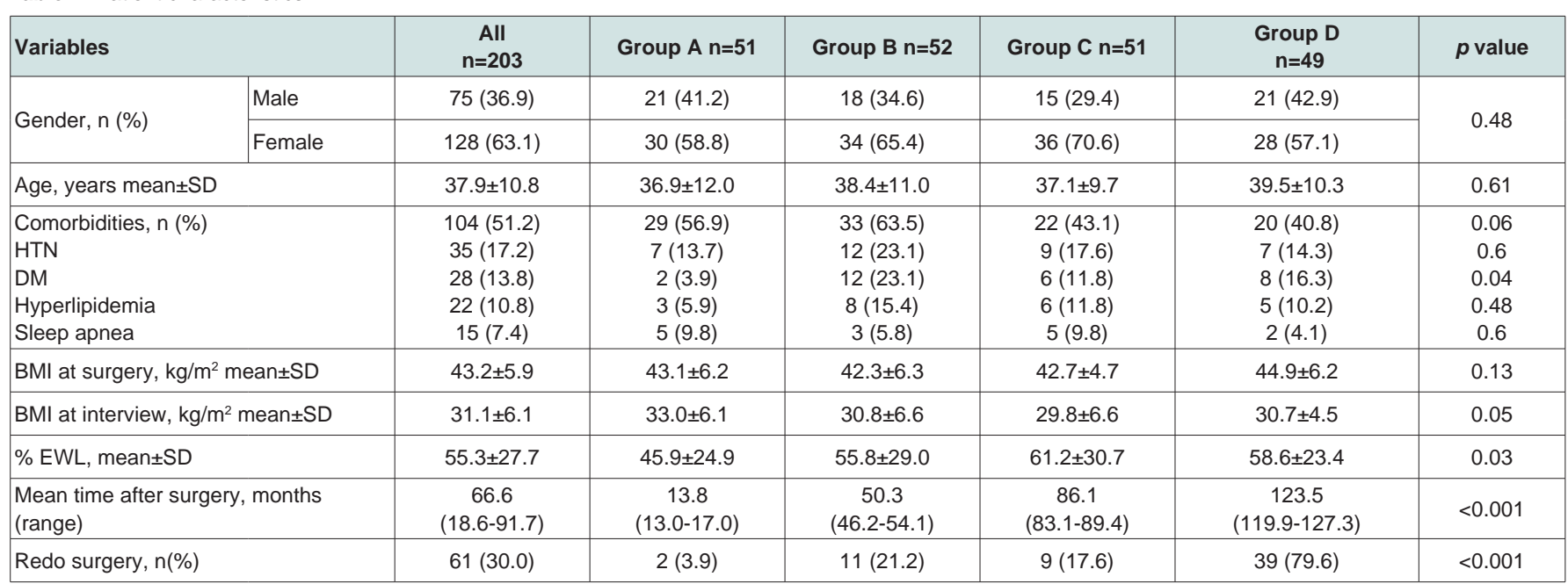

Table 2: PHQ-9 scores and quality of life measures.

\begin{tabular}{|c|c|c|c|c|c|c|}
\hline Variable & All & Group A & Group B & Group C & Group D & $p$ value \\
\hline PHQ-9 score & $3(0-6)$ & $4(1-7)$ & $3.5(0-9.8)$ & $2(0-6)$ & $2(0-4)$ & 0.36 \\
\hline $\begin{array}{l}\text { Self-esteem before surgery, points, mean } \\
\text { (range) }\end{array}$ & $5(2-7)$ & $5(3-6.5)$ & $5(2.3-7.4)$ & $3(1-6)$ & $5(3.3-7.8)$ & 0.07 \\
\hline Self-esteem after surgery, points, mean (range) & $9(8-10)$ & $9(8-10)$ & $9.5(8-10)$ & $9(7.5-10)$ & $9(8-10)$ & 0.94 \\
\hline Frequency of vomiting ${ }^{\mathrm{a}}$ & $3(1-4)$ & $3(1-4)$ & $2.5(0-4)$ & $2(0-4)$ & $3(1-4)$ & 0.8 \\
\hline Frequency of port inflations ${ }^{b}$ & $0(0-1)$ & $0(0-1)$ & $0(0-1.8)$ & $1(0-2)$ & $0(0-0)$ & $<0.001$ \\
\hline Surgery satisfaction, n(\%) & $177(87.2)$ & $46(90.2)$ & $41(78.8)$ & 45 (88.2) & 45 (91.8) & 0.45 \\
\hline
\end{tabular}

${ }^{a}$ Frequency of vomiting: 0 - no vomiting; 1 - vomits every day; 2 - vomits once a week; 3 - vomits once a month; 4 - rarely vomits.

${ }^{\mathrm{b}}$ Port inflations from surgery until interview day: 0 - up to $5 ; 1-5-10 ; 2-10-20 ; 3-$ more than 20. 
Table 3: Clinical and demographic differences between men and women.

\begin{tabular}{|l|c|c|c|}
\hline Variable & $\begin{array}{c}\text { Female } \\
(\mathbf{n}=\mathbf{1 2 8})\end{array}$ & $\begin{array}{c}\text { Male } \\
(\mathbf{n}=75)\end{array}$ & $\boldsymbol{p}$ value \\
\hline Age, years, mean \pm SD & $38.2 \pm 10.2$ & $37.5 \pm 11.7$ & 0.1 \\
\hline BMI before surgery, mean \pm SD & $43.3 \pm 5.7$ & $43.1 \pm 6.3$ & 0.75 \\
\hline BMI on day of interview, mean $\pm S D$ & $30.9 \pm 6.7$ & $31.4 \pm 4.9$ & 0.48 \\
\hline$\% E W L$ on day of interview, mean $\pm S D$ & $54 \pm 28.9$ & $57.5 \pm 25.4$ & 0.13 \\
\hline Redosurgery, n(\%) & $42(32.8)$ & $19(25.3)$ & 0.26 \\
\hline $\begin{array}{l}\text { Self-esteem before surgery, points, } \\
\text { mean } \pm S D\end{array}$ & $4.4 \pm 3.2$ & $5.4 \pm 2.6$ & 0.03 \\
\hline $\begin{array}{l}\text { Self-esteem after surgery, points } \\
\text { mean } \pm S D\end{array}$ & $8.7 \pm 1.9$ & $8.7 \pm 1.3$ & 0.8 \\
\hline Surgery satisfaction, $\mathrm{n}(\%)$ & $110(86.6)$ & $67(90.5)$ & 0.25 \\
\hline PHQ-9 score, mean $\pm S D$ & $5.3 \pm 6$ & $3.4 \pm 4.6$ & 0.01 \\
\hline
\end{tabular}

months after surgery, but a return of the mental health indices to the preoperative status 2 years later [8]. In addition, Ryden et al. even noticed worsening in depressive reactions 18 months after surgery [9]. A possible explanation for the contradiction lies in the fact that most studies have a relatively short follow-up period, and that different methods are used to evaluate depression and quality of life. However, our follow-up period was longer than that of most studies, and the fact that \%EWL increases significantly through the years while depression symptoms tend to decrease may strengthen this finding.

We also found that patients with a higher degree of depression symptoms had lower self-esteem after surgery, and were less satisfied with the procedure; but no correlation was found between depression symptoms and frequency of vomiting, number of re-operations, co morbidities, and age. This finding led us to the thought that success at losing weight is the key for improving the emotional status of patients, and that this success manages to overcome other factors that might have caused significant discomfort such as surgery complications. It is difficult to decide what is primary and what is secondary; do low self-esteem and depression after surgery impair the ability to lose weight or is it the other way around?

Lower self-esteem before surgery was correlated with higher degree of weight loss. Averbukh et al. also demonstrated a positive correlation between severity of depression before surgery (measured by BDI score) and weight loss [3]. This finding leads us to the thought that poorer psychological status before surgery may have a contributing role in weight loss, and stresses the need for more prospective studies examining the relationship between psychosocial status before surgery and success at weight loss.

Gender was also correlated with symptoms of depression and self-esteem; bariatric surgeries are more prevalent in women than in men, about $70 \%$ of patients undergoing bariatric surgeries are women. We found that although gender had no influence on the ability to lose weight, the amount of surgical complications after surgery, or satisfaction from the procedure, women tend to experience more depression symptoms than men. We also found that although men and women reached the same higher average selfesteem after surgery, women had a lower average self-esteem before the surgery, and therefore improved their self-esteem more than men. Dixon et al. found that women, especially of younger age with a poorer preoperative appearance evaluation, had greater falls in BDI score (between pre- and post-surgical scores) [5]. These findings raise the hypothesis that obesity creates a greater emotional burden on women, which is why surgical success has a greater emotional impact on women. Moreover, although we found that success in weight loss correlated with lower risk for developing symptoms of depression, women show a greater tendency for depression symptoms although they succeed in losing weight just like men, and that raises the hypothesis that among women the influence of other variables on weight loss is masked.

There are some limitations of the study. First, the limited number of patients participating in the study was low for multiple regression analysis. Second, no pre-surgical PHQ-9 forms were completed, so no conclusions could be made about the changes in depression symptoms for each patient individually. Further research is needed.

\section{Conclusions}

We found that weight loss following LGB has the greatest impact on both symptoms of depression and quality of life, and correlates with lower risk for developing symptoms of depression, higher selfesteem after surgery, and higher satisfaction with the procedure. Following LGB women have a greater tendency for developing symptoms of depression, but improved their self-esteem more than did the men. We recommended closed follow-up and psychologist involvement for women, who underwent LGB.

\section{References}

1. World Health Organization (1999) Obesity: Preventing and managing the global epidemic: report of the WHO consultation on obesity. Geneva, Switzerland.

2. Franco JV, Ruiz PA, Palermo M, Gagner M (2011) A Review of Studies Comparing Three Laparoscopic Procedures in Bariatric Surgery: Sleeve Gastrectomy, Roux-en-Y Gastric Bypass and Adjustable Gastric Banding. Obes Surg 21: 1458-1468.

3. Averbukh Y, Heshka S, El-Shoreya H, Flancbaum L, Geliebter A, et al. (2003) Depression score predicts weight loss following Roux-en-Y gastric bypass. Obes Surg 13:833-836.

4. Schowalter M, Benecke A, Lager C, Heimbucher J, Bueter M, et al. (2008) Changes in depression following gastric banding: a 5-to 7-year prospective study. Obes Surg 18: 314-320.

5. Dixon JB, Dixon ME, O'Brien PE (2003) Depression in association with severe obesity: changes with weight loss. Arch Intern Med 163: 2058-2065.

6. Scholtz S, Bidlake L, Morgan A, Fiennes A, El-Etar A, et al. (2007) Long term outcomes following laparoscopic adjustable gastric banding: postoperative psychological sequelae predict outcome at 5-year follow up. Obes Surg $17: 1220-1225$

7. Sanchez-Santos R, Del Barrio MJ, Gonzalez C, Madico C, Terrado I, et al. (2006) Long term health related quality of life following gastric bypass: influence of depression. Obes Surg 16:580-585.

8. Waters GS, Pories WJ, Swanson MS, Meelhelm HD, Flickinger EG, et al (1991) Long term studies of mental health after the Greenville gastric bypass operation for morbid obesity. Am J Surg 161:154-157.

9. Ryden O, Olsson SA, Danielsson A, Nilsson-Ehle P (1989) Weight loss after gastroplasty: psychological sequelae in relation to clinical and metabolic observations. J Am Coll Nutr 8:15-23.

10. Pinto-Meza A, Serrano-Blanco A, Peñarrubia MT, Blanco E, Haro JM (2005) Assessing depression in primary care with the PHQ-9: can it be carried out over the telephone? J Gen Intern Med 20:738-742.

11. Löwe B, Unützer J, Callahan CM, Perkins AJ, Kroenke K (2004) Monitoring depression treatment outcomes with the patient health questionnaire-9. Med Care 42(12):1194-1201 